\title{
UMA CONDIÇÃO CONTRAINTUITIVA Uma expatriação como experiência vivida
}

\author{
João Vasco Coelho \\ Iscte - Instituto Universitário de Lisboa, Centro de Investigação e Estudos de Sociologia \\ (CIES-Iscte), Lisboa, Portugal
}

\begin{abstract}
Resumo As práticas de expatriação vieram trazer novas condições de ação para indivíduos e organizações, para a gestão nas e das organizações. O presente artigo analisa as implicações desta prática de prestação de trabalho, com o suporte de 24 casos individuais de expatriação observados no contexto dos processos de internacionalização de cinco empresas, com génese ou presença nacional. Regista-se que, enquanto experiência vivida, ser (um) expatriado, numa empresa, pode corresponder a uma situação de trabalho e de vida permeável à experiência de um sentido de contradição e de difluência, uma circunstância que se associa, desde logo, a atributos objetivos de qualificação de uma expatriação, em si mesmo, enquanto situação de prestação de trabalho. Seis atributos são descritos e discutidos a este respeito, enquanto operadores de diferenciação de uma experiência pessoal, um acontecimento distante do até então percebido como comum.
\end{abstract}

Palavras-chave: internacionalização de empresas, expatriação, mobilidade internacional, experiência.

\section{A condition counterintuitive: exploring business expatriations as lived experiences}

Abstract Business expatriation practices have brought new conditions of action for individuals and organizations, as well as new managerial challenges for in and of organizations. This article analyzes the implications of business expatriations as contemporary global work setting, with the empirical support of 24 individual cases observed in the context of five international companies, born or present in Portugal. Results suggest that, as a lived experience, being or becoming expatriate in a company can correspond to a work and life situation permeable to the experience of a sense of contradiction and diffluence, a circumstance that is associated with inherent objective attributes of an expatriation as global work setting. Six attributes are described and discussed in this regard, as operators that contribute to differentiate expatriation personal experiences.

Keywords: business internationalization, business expatriation, international mobility, employee experience.

Une condition contre-intuitive: les expatriations comme des expériences vécues

Résumé Les pratiques d'expatriation ont créé de nouvelles conditions d'action pour les individus et les organisations, ainsi que de nouveaux défis de gestion pour les organisations. Cet article analyse les implications des expatriations comme cadre de travail mondial contemporain, avec le soutien empirique de 24 cas individuels observés dans le contexte de cinq entreprises internationales, nées ou présentes au Portugal. Les résultats suggèrent que, en tant qu'expérience vécue, être ou devenir expatrié dans une entreprise peut correspondre à une situation de travail et de vie perméable à l'expérience d'un sentiment de contradiction et de diffluence, une circonstance qui est associée aux attributs objectifs inhérents d'une expatriation comme milieu globale de travail. Six attributs sont décrits et discutés à cet égard, en tant qu'opérateurs qui contribuent à différencier les expériences personnelles d'expatriation.

Mots-clés: internationalisation, expatrié, mobilité internationale, expérience.

Una condición contraintuitiva: de la expatriación como experiencia vivida

Resumen Las prácticas de expatriación han traído nuevas condiciones de acción para individuos y organizaciones, así como nuevos desafíos gerenciales para las organizaciones. Este artículo analiza las implicaciones de las expatriaciones como un entorno laboral global contemporáneo, con el apoyo empírico de 24 casos individuales observados en el contexto e cinco empresas internacionales, nacidas o presentes en Portugal. Los resultados sugieren que, como experiencia vivida, ser o convertirse en expatriado en una empresa puede corresponder a una situación laboral y de vida permeable a la experiencia de un sentido de contradicción y difluencia, una circunstancia asociada con los atributos objetivos inherentes de una expatriación como escenario 


\section{Introdução}

A prestação de trabalho em contexto internacional constitui hoje um elemento-charneira na configuração de processos de transnacionalismo empresarial, uma prática de contributo crescente para os fluxos migratórios contemporâneos. A emergência de organizações multilocalizadas, públicas ou privadas, tem vindo a implicar uma forte deslocação espacial dos indivíduos como forma ou veículo de acesso à concretização de um percurso profissional. Neste quadro, as empresas transnacionais desempenham um papel especialmente relevante na recomposição das práticas de gestão da mobilidade associada à prestação de trabalho. Trata-se de um contributo particularmente significativo no contexto português, onde parte da mobilidade internacional de trabalhadores não se processa num contexto de iniciativa individual, mas enquadrada por práticas internas de empresas e de organizações (Peixoto, 1998).

Na pesquisa reportada pelo presente artigo, uma prática específica de prestação de trabalho em contexto internacional foi adotada como referente de problematização e de exploração empírica: uma expatriação. Para Kraimer et al. (2012), a expatriação e a gestão da expatriação representam (ainda) uma fraqueza no universo das empresas, sendo, todavia, decisivo o seu contributo para a concretização da estratégia de internacionalização de uma empresa (Black et al., 1999). Nos termos de Cerdin e Brewster (2014), regista-se que o foco das práticas observáveis nas empresas no domínio da gestão da expatriação e da mobilização internacional de trabalhadores é ainda de natureza maioritariamente reativa, imediatista e funcional, não se distinguindo, em igual medida, uma preocupação com o planeamento e a integração das contribuições individuais a longo prazo.

Em sentido diverso, uma expatriação é descrita por Peixoto (1998: 125) como um regime migratório "de topo", com uma componente reduzida de "risco", protagonizado por uma "elite migratória" detentora de atributos de autoridade ou de credenciais educativas diferenciadas, que apresentam uma capacidade (adicional) de circulação. Trata-se de um grupo numericamente reduzido da população, apesar de o poder por ele detido ser bastante superior ao seu peso demográfico (Peixoto, 1998), estimado em cerca de $5 \%$ do volume migratório global (Brookfield GRS, 2016), o que lhe confere importância estratégica e simbólica no domínio organizacional.

A representação de uma expatriação enquanto regime de prestação de trabalho associado à criação e à densificação de atividades produtivas de natureza transnacional (Bartlett e Ghoshal, 1991; Galbraith, 2000), apresenta contornos bivalentes. No discurso organizacional e gestionário, o acento laudatório predomina: o discurso 
oficial articula-se no sentido de apresentar os contextos de prestação de trabalho que implicam mobilidade e mobilização internacional como lugar de estímulo e de diferenciação. Ir para fora é apresentado como condição de prosperidade, uma oportunidade, uma escolha desejável, tendente à otimização dos recursos detidos. Numa perspetiva individual, vivida, são introduzidas nuances, relatos de insucesso, de paradoxo, dificuldades de integração concretas (Osland, 2000).

O sentido de divergência de representação de uma prática organizacional concreta inspirou o desenrolar (e a própria existência) da pesquisa reportada pelo presente artigo: um recurso desejável, porque anódino e valorizador de trajetórias pessoais, familiares e profissionais; uma situação de trabalho ambígua, aparentemente contraditória nos seus efeitos (Osland, 2000; Caligiuri e Bonache, 2016; Kraimer, Bolino e Mead, 2016), suscetível de constituir um acontecimento que suscita um sentido de rutura no plano pessoal, profissional e familiar (Lämsäa et al., 2016). O objetivo central da pesquisa realizada relacionou-se, neste sentido, com a necessidade de compreender o que justifica que a apresentação e a representação de um quadro específico de prestação de trabalho ocorram em termos aparentemente dissonantes, constituindo, em simultâneo, um lugar de oportunidade e de dificuldade, no contexto de uma empresa. Em função deste objetivo, o foco da análise foi colocado na perspetiva dos indivíduos expatriados, visando reconhecer, com esta opção, a importância e os efeitos da experiência de subjetivação individual de um conjunto de condições materiais de existência, retomando a aceção de Bourdieu (1989 [1977]). Com esta opção, visa-se elucidar o percebido (pelos indivíduos expatriados) pelo concebido em termos gestionários, definindo (as) condições de possibilidade e de inteligibilidade do vivido (e verbalizado) pelos indivíduos (Binswanger, 1971; Habermas, 1985; Dubet, 1996 [1994]). Com esta opção, procurou-se ver de perto, por dentro, em contextos empresariais concretos, os aspetos constitutivos de uma expatriação enquanto modalidade de prestação de trabalho, e as implicações subjetivas dessa prestação neste contexto, numa perspetiva individual.

\section{Uma expatriação: elementos de delimitação conceptual}

Perspetivada enquanto prática desenvolvida internamente numa empresa para a organização do trabalho e a gestão dos seus recursos humanos num contexto internacional, uma expatriação é tradicionalmente definida como um destacamento ou uma missão internacional (international assignment, no jargão gestionário anglo-saxónico) (Black et al., 1999), de duração tipicamente convencionada, (pré-)definida, uma duração tipicamente média ou longa (dois a três anos, em média) (Brookfield GRS, 2016), que envolve a deslocação física, internacional, por motivos profissionais, de um indivíduo, tipicamente detentor de um perfil especializado e/ou qualificado, uma operação de gestão de mobilidade profissional que decorre da iniciativa de um empregador, uma organização, ou por proposta/iniciativa (caucionada pela organização) do próprio indivíduo.

Respondendo à necessidade de empresas em processo de internacionalização constituírem ou manterem múltiplos mercados e centros de produção e/ou de 
distribuição, uma expatriação define um regime específico de desempenho de trabalho, localizável nos domínios organizacionais contemporâneos (Caligiuri e Bonache, 2016). A especificidade de uma expatriação, e a sua diferenciação de outros regimes ou movimentos de mobilidade associados à prestação de trabalho deriva: (a) da sua génese (organizacional), da existência e da subsistência de um enquadramento organizacional formal dos indivíduos no decurso do período de mobilidade; ( $b$ ) da existência de uma noção de duração, média ou longa; (c) de uma natureza transformacional, desenvolvimentista, associada à experiência da diferença, da distância e do desconhecido; e (d) da coexistência de diferentes referenciais de pertença, e da possibilidade correlativa de ocorrência de conflito e de hibridação simbólica e sociocultural, quer de práticas organizacionais, quer de trajetórias pessoais, familiares e profissionais.

Considerando a natureza tendencialmente temporária (McNulty e Brewster, 2017), desenvolvimentista (Doherty e Dickmann, 2009), potencialmente diferenciadora, da realização de uma expatriação, importa atender ao seu significado enquanto acontecimento crítico (Giddens, 1989 [1984]) no plano das relações sociais, um momento de potencial desencontro, descontinuidade e disrupção no quadro de uma trajetória pessoal, familiar e profissional. Uma expatriação é crescentemente identificada como contexto ao qual se associam dificuldades pessoais, profissionais e familiares. Importa considerar, a este propósito, que as condições de integração social e organizacional associadas a um quadro de expatriação podem ser entendidas como propícias à produção de paradoxo e contradição (Osland, 2000), à existência ou produção de atrito, de rutura(s) no campo das relações sociais e familiares (Halsberger e Brewster, 2008; Lämsäa et al., 2016). O indivíduo procura estar próximo, ainda que estando longe. Está na empresa, ainda que fora dela. $\mathrm{Na}$ sua especificidade time-dependent (Hippler, Brewster e Haslberger, 2015), importa considerar, deste modo, que a prestação de trabalho num contexto de expatriação pode definir, para empresas e indivíduos, um espaço-tempo social de exceção, uma situação crítica no quadro de relações sociais rotinizadas (Giddens, 1989 [1984]), marcada pela produção de diferença(s) (Deleuze e Guattari, 2004) e pela suspensão temporária (ou permanente) de um quotidiano (de papéis, tarefas, rotinas, responsabilidades) até então rotinizado. Face à possibilidade de disrupção ou suspensão de uma rotina até então existente, as práticas e a experiência de prestação de trabalho num quadro de expatriação podem representar, para os indivíduos expatriados, um motivo de condicionamento ou a oportunidade de definição de um género novo, inédito, distintivo, do ponto de vista identitário.

A possibilidade de um trabalhador expatriado constituir uma identidade de situação (Reynaud, 1992) decorre, deste modo, de uma rutura com uma situação (prévia) de trabalho e de emprego. A observar-se, trata-se de uma configuração de relação com um contexto de prestação de trabalho que pode implicar, para as organizações e para os indivíduos envolvidos, um custo elevado, dada a sua natureza contingente, exigente de recursos, de implicação, de investimento numa empresa de resultado incerto, imprevisível. Neste quadro, a "descoincidência de si consigo próprio" (Binswanger, 1971: 24) é possível, e implica práticas de subjetivação individual das condições materiais de existência (Bourdieu, 1989 [1977]), intimamente 
associadas à procura de manutenção, num quadro de pertenças múltiplas, síncronas e por vezes conflituantes ou concorrentes, de relações sociais caracterizadas pela confiança, por um sentido de estabilidade, de segurança ontológica (Giddens, 1989 [1984]). No caso em apreço, explorar, em termos analíticos, experiências e práticas de subjetivação implica explorar uma expatriação enquanto condição e nexo objetivo de integração organizacional, e os modos pelos quais se manifesta a orientação da ação dos indivíduos, assumindo, em termos teórico-metodológicos, a relação que se estabelece entre o material, o simbólico, o discursivo e o vivido (Habermas, 1985).

\section{Metodologia}

Com a pesquisa realizada, visou-se aprofundar o conhecimento de um quadro de prestação de trabalho específico (uma expatriação), um empreendimento cuja relevância decorre do impacto que lhe é atribuído ou atribuível, em termos socioeconómicos e organizacionais. A estratégia de pesquisa assumiu, em função da modelação deste desiderato, uma feição qualitativa, centrando-se na análise intensiva de uma seleção de campos de observação empírica. Com o uso de múltiplos contextos de análise, procurou-se ir ao encontro da profundidade de interpretação, do sentido de parcimónia e equilíbrio que tende a enformar uma análise e problematização de caso suportada em evidências recolhidas em múltiplos contextos empíricos (Eisenhardt e Graebner, 2007).

Atendendo ao horizonte de problematização teórica estabelecido para a pesquisa, a seleção de contextos de observação correspondeu à identificação de um conjunto de universos empresariais para a concretização da vertente empírica da pesquisa. Na identificação destes contextos, procurou-se atender à possibilidade de cada universo empresarial poder representar uma situação total, em relação à problemática em estudo (Ragin e Amoroso, 2011). A procura de diversidade, por um lado, e de tipicidade (de setores de atividade, de dimensão e volume de negócio, de trajetórias de internacionalização empresarial, e de práticas de expatriação e mobilidade internacional de trabalhadores), por outro, enformou a necessidade de considerar múltiplos contextos empresariais, supondo a existência de heterogeneidade nos domínios perfilhados em termos analíticos. Os cinco contextos empresariais considerados como espaço de observação empírica são apresentados de modo sintético no quadro 1.

Ao nível da recolha de informação empírica, foram empregues dois tipos de técnicas: a recolha e a análise de fontes estatísticas e documentais secundárias, públicas ou facultadas pelas empresas consideradas pelo estudo, um procedimento transversal à pesquisa, e a entrevista. No que concerne às fontes estatísticas e documentais utilizadas, o seu emprego visou localizar a realidade em estudo em termos macro. $\mathrm{O}$ foco das entrevistas foi duplo, em função do interlocutor considerado: a procura de caracterização e reconstituição das linhas de atuação empresarial, e das práticas de expatriação desenvolvidas num quadro de internacionalização da atividade produtiva, no caso de responsáveis de gestão de empresa; a exploração dos 


\begin{tabular}{|c|c|c|c|c|c|}
\hline 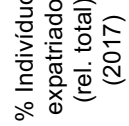 & $\frac{\stackrel{o}{a}}{\dot{v}}$ & $\frac{\widehat{o}}{\dot{\delta}}$ & 总 & $\begin{array}{l}\stackrel{\circ}{\circ} \\
\stackrel{\circ}{+} \\
+\end{array}$ & $\begin{array}{l}\stackrel{\circ}{\mathrm{N}} \\
\stackrel{0}{\circ}\end{array}$ \\
\hline 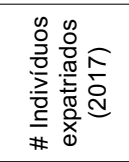 & $\stackrel{\mathscr{N}}{\sim}$ & ల్ల & $\stackrel{\circ}{\circ}$ & ্ָ & $\bar{\tau}$ \\
\hline 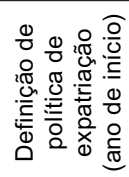 & $\stackrel{+}{\stackrel{N}{N}}$ & $\stackrel{\sim}{\sim}$ & 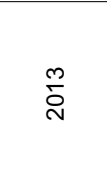 & $\stackrel{\circ}{\text { Dे }}$ & ঃे \\
\hline 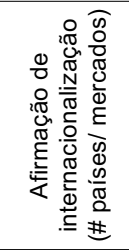 & 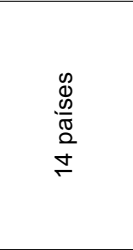 & $\begin{array}{l}\mathscr{0} \\
.0 \\
\frac{.0}{\pi} \\
\stackrel{0}{0} \\
\infty\end{array}$ & 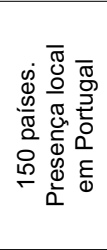 & 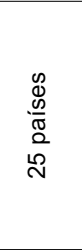 & 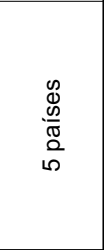 \\
\hline 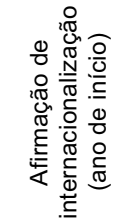 & @ & 吕 & 怘 & 过 & 吕 \\
\hline 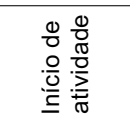 & $\stackrel{2}{\stackrel{2}{\sigma}}$ & 总 & ồ & 卓 & $\stackrel{\infty}{\stackrel{\infty}{\leftrightarrow}}$ \\
\hline 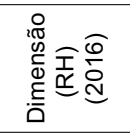 & $\begin{array}{l}\stackrel{\text { \& }}{\stackrel{N}{\sim}}\end{array}$ & $\begin{array}{l}\dot{8} \\
\dot{9} \\
+\end{array}$ & 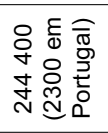 & $\begin{array}{l}\infty \\
\infty \\
\stackrel{\infty}{N} \\
\sim\end{array}$ & প্ণ \\
\hline 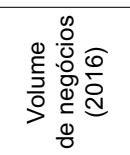 & 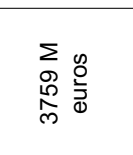 & 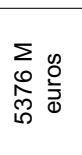 & 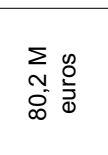 & 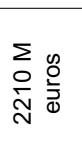 & $\begin{array}{l}\sum \\
\sum \\
0 \\
0\end{array}$ \\
\hline 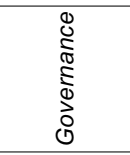 & 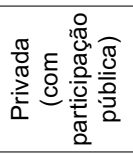 & $\begin{array}{l}\frac{\pi}{0} \\
\stackrel{0}{0} \\
\frac{2}{2}\end{array}$ & 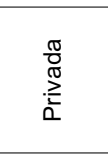 & $\begin{array}{l}\frac{\pi}{0} \\
\stackrel{0}{0} \\
\stackrel{0}{E} \\
0\end{array}$ & $\begin{array}{l}\frac{\pi}{0} \\
\substack{\pi \\
0} \\
0\end{array}$ \\
\hline 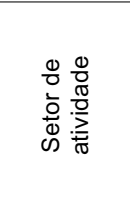 & 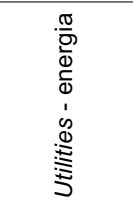 & 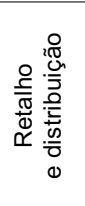 & 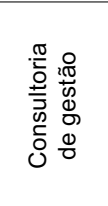 & 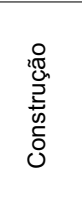 & 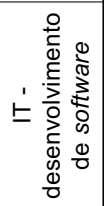 \\
\hline 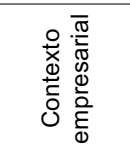 & 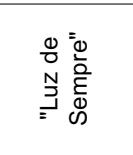 & 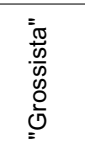 & 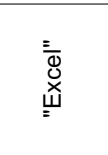 & 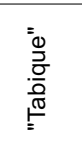 & $\stackrel{\substack{y \\
\stackrel{\infty}{p}}}{?}$ \\
\hline
\end{tabular}


atributos caracterizadores de uma expatriação enquanto experiência vivida, identificando tensões eventualmente existentes entre condicionantes estruturais e orientações da ação individual, no caso de trabalhadores expatriados. Foram realizadas 37 entrevistas individuais, em regime presencial ou remoto, 13 a responsáveis de gestão de empresa, 24 a trabalhadores cuja trajetória pessoal, profissional e familiar estava a ser ou tinha sido pontuada, com maior ou menor intensidade, pela prestação de trabalho num quadro de expatriação (assim definido e referido pelas empresas).

As entrevistas a responsáveis de gestão de empresa foram presenciais, e tiveram uma duração média de 80 minutos. Das 24 entrevistas a trabalhadores expatriados, 13 tiveram lugar em regime remoto, via Skype ou interface análoga, sendo, em quatro destes casos, assegurado o registo apenas em áudio, devido a debilidades de infraestrutura de comunicação. As entrevistas a trabalhadores expatriados tiveram uma duração média de 120 minutos. A título sensibilizador, fez-se uso de um critério de saturação de informação (Strauss e Corbin, 1998) na limitação do número de casos individuais considerado em/para cada empresa.

Dada a orientação estratégica da pesquisa e o horizonte de problematização perfilhado, procurou-se constranger, de modo deliberado, o perfil dos indivíduos a entrevistar, à imagem do observado na identificação dos contextos empresariais adotados como instância de análise empírica. Cinco critérios de seleção foram partilhados com o ponto de contacto existente em cada contexto empresarial, tipicamente um gestor de recursos humanos indigitado para o cumprimento da função de regulação do acesso ao campo empírico (gatekeeping) (Shenton e Hayter, 2004). O primeiro destes critérios diz respeito à trajetória pessoal e profissional dos indivíduos, e à intensidade, em termos relativos, de internacionalização desta trajetória. A condição presente em relação à mobilidade (expatriado vs. repatriado) definiu um segundo critério de seleção. A duração da mobilidade atual ou mais recente (em caso de regresso, de repatriação) constituiu um terceiro critério. O ponto de articulação biográfica (início, expansão, estagnação, desfecho de trajetória) definiu um quarto critério, e, por fim, a condição familiar (existência de filhos, de ascendentes dependentes, de família acompanhante) delimitou um último fator a considerar.

Os materiais empíricos reunidos foram objeto de análise e categorização temática com o apoio de software específico (MaxQDA v. 12). O trabalho analítico procurou articular a perspetiva gestionária e organizacional com as perspetivas individuais relativas a experiências concretas, vividas, de prestação de trabalho referidas como constituindo uma expatriação. Uma perspetiva dupla foi adotada na explanação dos resultados da análise dos materiais empíricos: (a) a exploração de regularidades observáveis entre os diferentes contextos e casos considerados (cf. secção seguinte); e (b) a discussão de aspetos particulares, salientes além das regularidades observadas (cf. secção: “Uma expatriação: um lugar de difluência, uma condição contraintuitiva"). Atendendo ao dever e ao compromisso de confidencialidade e de manutenção do anonimato inerente às tarefas de recolha e tratamento de informação empírica, a identidade dos contextos empresariais e dos indivíduos entrevistados em cada contexto foi omitida, na apresentação e na discussão dos resultados da pesquisa. 


\section{De uma expatriação como experiência vivida}

$\mathrm{Na}$ análise que se apresenta, a caracterização da experiência individual das práticas em uso em cada contexto empresarial considerado é concretizada com o apoio de ilustrações empíricas procedentes do material empírico que foi recolhido, enunciados cuja função primordial é a elucidação do argumento apresentado a cada momento. Em relação ao modo como uma expatriação se constituiu, para os indivíduos expatriados que foram entrevistados, enquanto objeto de uma experiência vivida, importa atender, a título de regularidade, a três elementos empíricos, que se analisam de seguida: (a) uma expatriação constitui (é vivida como) um acontecimento, uma experiência pessoal distante do (até então) comum; (b) uma expatriação constitui (é vivida como) uma experiência difluente, permeável à contradição e à ambivalência; $(c)$ existem atributos objetivos de uma expatriação que contribuem para a sua reconstituição, numa perspetiva individual, como uma situação de prestação de trabalho (que também é) difícil.

Uma experiência de expatriação é, de facto, uma experiência. Nas entrevistas realizadas, foram múltiplos os relatos que fazem equivaler uma expatriação a uma experiência pessoal, tendendo o "estar fora, pela empresa" [Nuno] a fazer-se apresentar e representar como um acontecimento, como uma situação (de trabalho, de existência) distante do que era até então comum, para os indivíduos. Este é um dado que é desde logo mobilizado, em termos discursivos, pelas empresas: associar uma expatriação a um campo de experiência pessoal constitui, para uma empresa, uma possibilidade retórica, um recurso discursivo que contribui para a sua apresentação enquanto espaço ou agente social e económico onde há oportunidades e vantagens, uma diferenciação que é concedida. Importa "ganhar mundo" [grupo "Tabique"], "abrir a caixa", "sair da zona de conforto" [grupo "Luz de Sempre"]. Por seu turno, a enunciação, pelos indivíduos, da existência de uma experiência pessoal tende a decorrer da necessidade de dar expressão a uma novidade, procurando fazer reconhecer (pelos outros) a existência de um acontecimento distante do (até então) comum.

Para os indivíduos entrevistados, estar expatriado corresponde a "um destacamento, um long-term assignment" [Silvestre], a "uma missão" [Joana], a "uma mobilização" [Duarte], a "estar deslocado" [José], a "estar fora, em serviço" [Francisco], a "ser externo num projeto" [Filipa], a "estar fora, pela empresa" [Nuno], a "ir pela empresa para outra geografia" [Augusto]. Uma expatriação define, neste sentido e deste modo, uma experiência que se tem, que se adquire, que se pode adquirir, de uma "distância do que é comum" [Carlos], passível de ser apropriada enquanto recurso de especialização competitiva (e comparativa). Trata-se, numa outra perspetiva, de uma experiência de "capacitação" [Nuno] individual que decorre em ambiente controlado, na medida em que há um enquadramento formal que persiste, "uma almofada", nos termos do Augusto. Trata-se de uma possibilidade de "ganhar mundo" [Duarte], de "estar fora" [Nuno] sem sair de dentro:

A garantia de manter uma base, de ter um retorno, faz com que estas missões sejam mais interessantes, pela estabilidade. Acho que estas experiências de mobilidade 
dentro de uma empresa têm o melhor de dois mundos: o mundo da experiência lá fora, com uma base, uma estrutura [Carlos].

Nunca me senti um emigrante, que vai para outro lado para ganhar a vida, porque sabia que estava lá por um tempo determinado, e que tinha alguém por trás a pagar o ordenado. Isso ajuda muito. Estava lá, no fundo, numa comissão de serviço [Gil].

A empresa faz questão de expor os objetivos, explicar o que é que se passa. Recentemente, o responsável pela geografia disse: "Isto não está famoso, não há projetos, mas a estratégia da empresa é assegurar pelo menos mais um ano". Como colaborador com um contrato aqui não é totalmente confortável, mas a empresa, pelo menos em relação a mim, faz questão de me deixar confortável. [...] Sendo eu um recurso que vem de Portugal, a possibilidade de regresso é uma almofada [Augusto].

Para um expatriado, uma expatriação poderá definir e ser apropriada, por um lado, enquanto experiência de autonomia, de "capacitação" [Nuno], de "crescimento pessoal" [Rui, Violeta]. Poderá tratar-se de uma "mais-valia" [Rui], de um marcador de diferenciação no plano de uma trajetória pessoal, profissional, familiar. Há uma experiência de "crescimento" [Rui], porque há "ganhos de perspetiva" [Violeta, Duarte], de "termos de comparação" [Heitor], porque há a experiência pessoal de uma diferença, de um contraste que opera por oposição, na relação com o herdado, com o anteriormente vivido. "Sair da zona de conforto" [Duarte] implica esta oposição, o acesso a um contraponto em relação à experiência prévia, um referente cuja apropriação pode suscitar um distanciamento subjetivo, um sentido de reflexividade pessoal, de cálculo, de perspetivação:

Com esta mobilidade, coloquei-me à experiência em situações de mudança, e descobri ou criei em mim coisas... adaptei-me, sinto que consegui [ênfase] adaptar-me a uma situação nova, a vários níveis. Sinto que consigo adaptar-me a outros ambientes de trabalho, completamente diferentes. Sinto que há em mim reservas de reação que não conhecia. Pus-me à prova, no fundo. E a experiência veio confirmar que foi bom tê-lo feito. Mudei, aprendi sobre mim... de uma forma que provavelmente só uma situação deste estilo me poderia mostrar [Antónia].

Uma experiência difluente. A associação de uma expatriação à existência de uma "mais-valia" [Rui] não é, porém, unívoca e inequívoca. Atendendo ao observado em termos empíricos, as "condições de viagem e integração" não são necessariamente conhecidas na íntegra (pelas próprias empresas e pelos indivíduos), os "custos (psicológicos e financeiros)" nem sempre são "reduzidos ao mínimo" (Peixoto, 1998: 141). Em termos analíticos, da experiência das condições objetivas de prestação de trabalho, regista-se um sentido de difluência que é significativo. Há, no plano da experiência vivida, danos invisíveis infligidos nas relações. Enquanto experiência vivida, ser ou ter sido (um) expatriado pode consubstanciar uma provação, uma "dessincronização" [Xavier], um "desenraizamento" que implica " 
esforço" [Mário], penosidade, uma "corrida" que cria desordem, "individualismo, distanciamento" [Duarte]:

Foi uma experiência. Para mim, foi sempre uma experiência de desenraizamento. Sabia, grosso modo, para o que ia, mas para mim foi sempre um desenraizamento. A expatriação, para mim, é um desenraizamento. No meu caso, consegui recuperar a minha raiz cá. Muitos têm de enraizar noutra parte. O que eu não concebo para mim. Esta é uma realidade muito comum, muito presente, hoje em dia, também nesta empresa. A realidade é esta: ou há raízes para a empresa, ou há raízes para o colaborador. A conciliação não é possível [Mário].

Acho que aprendi a estar sozinho. Em paralelo, ajudou a desenvolver o trabalho em equipa. Nós estávamos muito tempo uns com os outros. Estávamos muito absorvidos no trabalho. Para mim, o pior dia da semana era o domingo, que era quando parava e tinha mais tempo para pensar. Acho que é uma experiência que tem mais pontos negativos do que positivos [Tiago].

Eu não estou bem num lado nem no noutro. Posso ser gozado, um gozo saudável, no dia-a-dia, como sendo alguém do outro lado. Se saio daqui mais cedo, dizem que estou com horário inglês. Lá, se sair mais tarde, dizem que estou com horário português. Há uma dessincronização: nunca estou com o horário certo [Xavier].

Esse é o meu tema de vida de há três ou quatro anos para cá: sinto que vivo dentro de uma mala de viagem [Dinis].

Há um distanciamento. Se perdi amigos pelo caminho? Sim. Se ganhei amigos pelo caminho? Muito poucos. Não sei se é típico, falo apenas por mim [Duarte]

O que é, afinal, um expatriado? Para um expatriado, o que representa uma (a sua) expatriação? "Não o uso, não gosto do termo. Para mim, é um termo pejorativo: é um indivíduo que é posto fora da pátria, por indecente e má figura" [Gil]. No referente à experiência, em termos vividos, de uma expatriação, regista-se um significativo efeito de difluência no modo como as práticas de gestão e a experiência destas são representadas e apropriadas pelos indivíduos expatriados. Trata-se de uma prática que tanto pode definir ou fazer-se definir como "uma emigração de luxo" [Rui], "um el dorado" [Nuno], "uma oportunidade boa" [Silvestre], ou, ao invés, como uma "experiência marcada pelo estigma do privilégio" [Duarte], o corolário de uma "necessidade" [Dinis], de alguém que "teve de ir para Angola para poder trabalhar" [Nuno]. A resposta à questão apresentada não é óbvia, imediata, evidente.

Para um conjunto dos indivíduos expatriados que foram entrevistados, a necessidade de mediar um sentido de difluência, é passível de ser vivida como um acontecimento excecional, de "crescimento" [Rui, Violeta] - um "crescimento" que distingue, que singulariza (um trajeto, uma identidade, uma experiência específica de trabalho). Organizar uma condição de desconjunção, de difluência, tende a implicar um investimento subjetivo, uma "ginástica" [Heitor] apensa à 
necessidade de conciliação de dimensões de vida, cujo resultado e efeitos não são totalmente previsíveis ou passíveis de controlo, pelos indivíduos (e pelas próprias empresas). Da mediação, da procura de (re)conciliação, tende a decorrer um resto, um sentido difuso, refratário, de ambivalência: há ganhos e há perdas, há luz e há sombra, há "facilidades" [Francisco] e há dificuldades, em termos vividos.

Por referência a um campo de representação heteróclita, as definições pessoais apresentadas pelos indivíduos entrevistados tendem a fazer ecoar um elemento de ambiguidade, de privação, de penosidade. Para o José, é próprio (é definidor) de uma expatriação estar "sem a família". "Ser expatriado" define uma condição de desempenho de trabalho marcada pela excecionalidade, no entender do Duarte: "Não há horário, é o que tiver de ser. Entende-se que a questão da legislação não se aplica propriamente, porque se está fora". Ser (um) expatriado corresponde, nos termos do Carlos, a "uma situação de trabalho nas empresas", uma situação centrada na prestação de trabalho, que implica, no entender do Duarte, "vender a alma à empresa". A expatriação apresenta-se, neste sentido, como um campo onde é (será) possível constituir, no melhor cenário possível, uma identidade de situação (Reynaud, 1992): não se éum expatriado, está-se ou esteve-se expatriado. A adesão que se observa, por parte dos indivíduos e das empresas, ao invés de outras categorias formais associadas à prestação de trabalho, não é imediata, unívoca, inequívoca. Trata-se de um campo que é percebido como sendo portador de ambiguidade, de impureza(s), como ilustrado, em termos empíricos, pela referência reiterada a imperfeições de articulação com o universo familiar, e à dificuldade de consumar o (um) regresso, num contexto de repatriação.

A conciliação familiar implica uma "ginástica" [Heitor], uma conciliação de partes porventura dificilmente conciliáveis, por via de práticas de restauração, de reparação, de mitigação do dano infligido pela ausência, pela distância física, pela intermitência de contacto próximo. Num momento de repatriação, aquele que regressa - a um grupo, a um papel, a uma função, a uma outra situação - é o mesmo. Mas não é igual. "Deixar de ser o senhor engenheiro, [...] o rei do pedaço" [Isaac], "ter ir de novo para a fila do pão" [Isaac], garantir a preparação para "a distância das coisas" [Filipe], são enunciados que ilustram práticas particulares de recomposição identitária, de acento difluente, que exprimem ganhos, que denotam perdas, associados ao momento do regresso.

Como é defendido por um dos indivíduos entrevistados (Enzo), uma expatriação diz respeito a uma situação de prestação de trabalho que é "assumida com dificuldade pelas empresas". O uso e a definição dos termos expatriação e expatriado é tímido, tergiverso, aparenta ser, de facto, assumido com dificuldade pelas empresas e pelos próprios indivíduos: apenas 30\% dos indivíduos expatriados entrevistados (7 em 24) se apresentaram como sendo ou tendo sido "expatriados", mobilizando a expatriação como categoria ou referência de identificação. Os outros (e.g., a empresa, os "recursos humanos", os "outros expatriados", "os locais", "os que não vão") tendem a ser aqueles que empregam, sem equívoco ou embaraço, os termos expatriado e expatriação. Ser ou ter sido (um) expatriado aparenta definir, neste sentido, mais uma designação do que um desígnio. Uma designação que é fundamentalmente empregue pelos outros. 
Uma experiência (que também é) difícil. Em termos analíticos, seis operadores objetivos de caracterização de uma expatriação foram identificados como elementos contribuintes para a sua qualificação enquanto situação de prestação de trabalho que se presta, numa perspetiva individual, a ser associado com um sentido de dificuldade e contradição. A exposição a estes operadores tende a ser perspetivada, em termos subjetivos, como o lugar de contacto com uma fronteira (social, simbólica, cognitiva), razão de enunciação de "descobertas" [Antónia], passíveis de ser encapsuladas como sintoma de "crescimento pessoal" [Rui].

a) O transitório que dura. O uso de práticas de periodização formal da prestação de trabalho pelas empresas é especialmente saliente num contexto de expatriação, contribuindo para colocar os indivíduos expatriados, desde um primeiro momento, numa relação particular (linear, não circular) com o tempo. A escansão do tempo em episódios, o uso do transitório durável (e.g., o adiamento, a extensão de uma expatriação) como lugar de fundamento de práticas de gestão e organização do trabalho pode instituir, em si e por si mesmo, um sentido de "deslocamento" [Augusto], de ocorrência de uma experiência pessoal: "No caso de Moçambique, eu fui para lá seis meses, e acabei por ficar seis anos" [Filipe]; "Eram dois anos... estamos em 2017, já passaram sete anos" [Aurélio]. A periodização formal de uma expatriação afigura-se, neste sentido, uma prática de gestão sensível, ao contribuir para a constituição de um horizonte particular de expectativa (e.g., o sentido de brevidade da expatriação), e um sentido de reversibilidade da experiência e dos efeitos da experiência vivida, que influenciam a natureza das relações estabelecidas localmente (e.g., superficiais, instrumentais, holísticas), e processos de decisão pessoal nevrálgicos para o indivíduo e para a empresa (e.g., levar ou não família).

b) As mudanças organizacionais: a empresa éa mesma, mas não fica igual. A subsistência da integração formal numa organização, no decurso de uma expatriação, comporta implicações específicas. O espaço organizacional é o mesmo, mas não fica igual. Pela abertura (de relações, de fronteiras sociais e cognitivas) que tende a implicar, a mobilidade associada a uma expatriação contribui, em si mesma, para este efeito. A integração organizacional pode ser enformada por um posicionamento liminar, um estar dentro, estando fora: em termos formais, os indivíduos expatriados estão dentro da organização; em termos substantivos, em casos e contextos particulares de relação, estão fora do perímetro de relação, de decisão e de possibilidade de influência. "Não é fácil", refere o Filipe, manter um sentido de identificação com a empresa, "quando se está fora". Além de constituir e representar um enquadramento formal que persiste, "uma almofada", nos termos do Augusto, a subsistência de uma relação formal com a empresa permite a manutenção de um posto de observação sobre a labilidade do espaço, das práticas, dos referentes e das decisões organizacionais, uma circunstância que, em diferentes casos considerados, influenciou o curso da ação e das decisões daquele que se encontra expatriado. Quando regressava a Portugal, o Francisco observava que a "casa 
[a empresa], as pessoas já não eram as mesmas". Numa outra perspetiva, a persistência de um enquadramento organizacional pode contribuir para organizar a expectativa de existência de um regresso (a um ponto de origem), uma circunstância que adensa a pressão para a validação de um reconhecimento visado, a resolução de uma descontinuidade eventualmente vivida no decurso de uma expatriação.

c) A lassidão do laço. Uma expatriação aumenta a probabilidade de contacto com a alteridade, tende a multiplicar as relações que são mantidas, que importa manter, pelos indivíduos expatriados. Nos contextos e nos casos considerados em termos analíticos, não se registou um débito de oportunidades de relação e de identificação, mas sim a acumulação e a concorrência destes, uma circunstância cuja regulação se afigura capaz de definir, em si e por si, o objeto de uma experiência pessoal. Este é um eixo em relação ao qual foi possível observar diferentes nexos na ação dos indivíduos entrevistados, opondo-se a insularidade e o refúgio protetor numa "bolha de semelhantes" [Carlos], numa "família de substituição" [Mário], à abertura holística (ao outro, à cultura local) [Miguel] e à sociabilidade afinitária, utilitária, como modos de (re)organização de um sentido comunal de pertença. No entender do Filipe, um projeto internacional, na sua duração, "faz e desfaz relações". Numa e com uma expatriação, há "laços que se ganham" [Heitor], há laços que se perdem, há laços que ficam. Neste quadro, a existência de uma "família de substituição" [Mário] associa-se a um sentido de proximidade que deriva de um "efeito de semelhança" [Heitor], de uma situação em que "todos estão fora do seu ambiente natural" [Aurélio]. A lassidão do laço constitui, a este propósito, um efeito, por um lado, da aparente superficialidade das relações estabelecidas num contexto de expatriação, e, por outro, da ausência, da intermitência ou da rarefação do contacto que assegura a preservação de um sentir em comum, com aqueles que são valorizados enquanto referentes afetivos e expressivos nucleares: o cônjuge, os filhos, a família, os "amigos-amigos" [Dinis].

d) Adescontinuidade (contextual e funcional). A prestação de trabalho em regime de expatriação apresenta-se, nos contextos empresariais considerados, como uma situação que se presta à descontinuidade ou à rutura do enquadramento funcional prévio dos indivíduos. A descontinuidade de funções é, muitas vezes, um acontecimento imprevisto, sendo deficitária, por vezes, a preparação, o tempo, a disponibilidade individual ou o apoio formal para concretizar as aprendizagens implicadas no desempenho das funções atribuídas. A descontinuidade é, por vezes, dupla: descontinuidade, em sentido objetivo, em relação a um papel ou função anteriormente desempenhado pelos indivíduos; descontinuidade, em sentido objetivo e/ou subjetivo, em relação à expectativa de papel a desempenhar em contexto de expatriação. A definição clara, formal, de um papel a desempenhar, sugere um sentido de coerência, de ordem, de cuidado, de previsibilidade. Contribui para mitigar o sentido de descontinuidade, a magnitude (desta), aos olhos dos indivíduos. Numa maioria de casos considerados, as atividades de trabalho a desempenhar pelo trabalhador expatriado caracterizavam-se por uma diferença qualitativa em 
relação a desempenhos anteriores, diferindo também o trabalho efetivamente desempenhado do declarado ou planeado, em termos formais.

e) A imperfeição da articulação com o universo familiar. Nos casos considerados, há menção manifesta e recorrente à dificuldade de conciliação da prestação de trabalho em contexto de expatriação com o universo familiar. Há arranjos tendencialmente imperfeitos, sitiados, curto-circuitados, de domínios e de referentes nucleares de vida (e.g., o trabalho, a família, o tempo). O esforço aparenta ser reflexo: implicando esforço, trata-se de arranjos que sinalizam a existência de relações que se encontram em esforço (em tensão). Para o Duarte, a família representa "a raiz que fica". Para o José, a própria condição de "estar sem a família" é, em si mesma, uma condição definidora da prestação de trabalho num regime de expatriação: "Eu estava deslocado... foi uma experiência de expatriação: estive sem família... a minha mulher e filhos falavam de coisas que eu não sabia o que eram". Conciliar (ter de conciliar) pode definir, para os indivíduos, uma tarefa, um lugar de tensão, de dispêndio (previsto ou imprevisto) de recursos, de fadiga. Não sem surpresa, a dificuldade de conciliação familiar constitui o principal motivo apenso à (re)negociação das condições de mobilidade associadas a uma expatriação, visando a introdução de um elemento de intermitência [Nuno, Xavier], ou de copresença física da família nuclear [Miguel]. A necessidade de conciliação e a existência de tensão não constituem necessariamente, para os indivíduos entrevistados, um dilema insuperável. Contribuem, porém, para suscitar um envolvimento parentético, condicionado, com a situação de expatriação, para retalhar a experiência vivida, repartindo relações e domínios de vida.

f) A dificuldade de consumar o (um) regresso. O regresso (a repatriação) constitui um momento de dificuldade (de gestão) para as empresas analisadas. Para o Carlos, o regresso é "o momento, um momento com $m$ grande". No seu regresso a Portugal, na empresa "V\&V", o Carlos tinha "metade de uma coisa à sua espera". Por défice de planeamento ou de preparação pessoal, e a ausência de oportunidades que fomentassem o reconhecimento visado, o Carlos considera que viveu "o choque de chegar". No caso do Gil e do Filipe, a preparação antecipada ("meio ano" que foi acordado com a empresa, no caso do Filipe) possibilitou o equilíbrio das expectativas, a redução de distâncias (sociais e culturais), no momento do regresso. O Isaac, no regresso a Portugal, teve de "reaprender a viver, teve de reaprender a viver com os amigos". O regresso constitui o momento de afirmação, de explicitação da congruência ou da incongruência, da polaridade eventualmente subjacente à articulação estabelecida entre práticas institucionais e experiências individuais, num período temporal específico. Trata-se do momento que implica a resolução da rangência subjacente a esta articulação. Um momento que pode espelhar uma "indefinição" [Miguel] de base, no plano da experiência individual, que exprime um encontro ou um desencontro de necessidades, de motivações. A dificuldade é, muitas vezes, dupla: uma dificuldade em integrar o que foi vivido e desempenhado, em termos situacionais, no âmbito de uma trajetória pessoal, profissional e familiar; uma dificuldade em fazer reconhecer o vivido 
e o adquirido num espaço organizacional, ele próprio bastas vezes recomposto, em relação ao existente no momento da partida.

\section{Uma expatriação: um lugar de difluência, uma condição contraintuitiva}

No contexto da literatura gestionária, os processos de internacionalização das empresas tendem a ser considerados como uma realidade homogénea, como uma inevitabilidade de efeito benigno (Costas, 2013). À luz desta perspetiva de análise, tende a tomar-se igualmente como inequívoca, como natural, a valorização de orientações cosmopolitas, desterritorializadas, de apego à mobilidade física, geográfica, internacional, como a que é tipicamente carreada por um processo de expatriação. Em sentido próximo, em Portugal, em empresas em processo de internacionalização como as consideradas na pesquisa descrita pelo presente artigo, é possível identificar práticas de expatriação que surgem enformadas por um sentido de seletividade, de distintividade, dando forma à noção de que a prestação de trabalho em contexto de expatriação não é "para qualquer um" (Câmara, 2011:59).

Os resultados da presente pesquisa apontam num sentido diverso do enunciado, salientando a possibilidade da experiência de ser (um) expatriado, numa e por uma empresa, constituir uma realidade marcada, não apenas pela possibilidade de encetar novas aprendizagens, mas também pela exposição aos efeitos da difluência, da contradição normativa, da ambivalência. Como ilustrado no ponto anterior, esta é uma circunstância que é carreada, desde logo, pelos operadores de configuração e qualificação objetiva de uma expatriação, que podem implicar um investimento subjetivo, por parte daquele que se encontra expatriado, na conciliação de partes, na reparação de relações, na resolução da rangência que surge apensa a uma experiência que pode fazer-se apresentar como que imperfeita, desconjunta.

$\mathrm{Na}$ análise realizada, a experiência (Dubet, 1996 [1994]) emerge como figura de síntese, um signo capaz de designar uma situação e um enquadramento situacional na sua especificidade e na sua globalidade, articulando elementos de contexto com atributos caracterizadores da ação individual. Falar de uma experiência constitui, como observado, para os indivíduos entrevistados, um modo de nomear um acontecimento particular, distante do que era até então (para si) comum. Uma experiência pessoal, à partida, é algo dificilmente repetível, não se trata de um efeito de uma fórmula passível de repetição deliberada. Em sentido fenomenológico, o lugar de génese de uma experiência radica na descontinuidade, num sentido de transformação da relação que é estabelecida com a ordem social até então existente, que é difícil de institucionalizar, de repetir, de rotinizar (Dubet, 1996 [1994]).

A instauração fundacional de um sentido de periodização, de ciclitude, a probabilidade de existência de um regresso ao ponto de origem, a dificuldade de articulação com o universo familiar, a rarefação de relações sociais preexistentes, a labilidade da regra organizacional, a existência de decisões e de mudanças organizacionais não inteiramente passíveis de antecipação. Pelas suas implicações, os atributos objetivos apresentados contribuem para reconstituir uma expatriação 
como lugar de difluência, uma condição de experiência(s) contraintuitiva(s), distantes do comum, pela circunstância de ter lugar no quadro de espaços organizacionais formais, dotados de regras, de normas formais às quais os indivíduos tendem a associar um sentido de continuidade simbólica e institucional, uma expectativa de integridade (da empresa) e de integração (na empresa).

Como diferentes ilustrações empíricas apresentadas indiciam, as práticas e as regras organizacionais revelam-se insuscetíveis de definir integralmente, em termos formais e normativos, uma expatriação como situação de prestação de trabalho. No caso em apreço, se se afigura, no plano empírico, que o sentido e a eficácia das práticas organizacionais não são totalmente determinados pelas empresas (e.g., a existência de descontinuidades funcionais, de periodizações moventes, de exceções à norma formal instituída, a dificuldade em gerir uma repatriação), a lógica da ação individual não pertence totalmente aos indivíduos expatriados, remetendo a sua coerência interna para o contexto das práticas organizacionais e da experiência vivida das mesmas, no quadro de uma trajetória prévia, de uma configuração de relações mantidas in situ. Esta é uma circunstância passível de gerar um sentido de desconjunção (contraintuitiva), em termos relacionais e subjetivos, um dado cuja consideração é incontornável em termos de gestão, na medida que, para muitas empresas, os resultados de um processo de internacionalização depende do recurso bem-sucedido a práticas de expatriação de trabalhadores, e, para muitos trabalhadores, a manutenção da relação contratual, do desenvolvimento de uma carreira organizacional, se apresenta condicionada, no momento presente pela angariação (e pela demonstração) de experiência de prestação de trabalho em contexto internacional.

\section{Conclusões}

Uma expatriação define uma prática organizacional e um domínio de experiência de trabalho e de vida que constituem um espelho e um veículo de processos contemporâneos de globalização económica. Como sugerido pelo presente artigo, estes processos têm vindo a promover a diferenciação das experiências individuais de prestação de trabalho no seio das empresas, por via da constituição de quadros de ação de onde tendem a sobressair implicações difluentes, uma circunstância resistente a intuitos de controlo unificante de natureza gestionária. Como ilustrado, no caso vertente, o sentido de difluência é vivido como uma experiência, um acontecimento distante do comum, carreado pela própria configuração material e gestionária de uma expatriação enquanto quadro de prestação de trabalho, um lugar cujos contornos e destino não são totalmente controlados pelas partes em presença, e onde, do encontro da objetividade das regras e das práticas organizacionais com a racionalidade e as atividades dos atores, não decorre uma adequação total, absoluta. 


\section{Referências bibliográficas}

Bartlett, Christopher, e Sumantra Ghoshal (1991), Managing across Borders. The Transnational Solution, Boston, Harvard Business School Press.

Binswanger, Ludwig (1971), Introduction à l'Analyse Existencielle, Paris, Les Editions de Minuit.

Black, J. Stewart, Hal Gregersen, Mark Mendenhall, e Linda Stroh (1999), Globalizing People through International Assignments, Nova Iorque, Addison-Wesley.

Bourdieu, Pierre (1989 [1977]), O Poder Simbólico, Lisboa, Difel.

Brookfield GRS (2016), Global Mobility Trends Survey - 2016, Nova Iorque, Brookfield.

Caligiuri, Paula, e Jaime Bonache (2016), “Evolving and enduring challenges in global mobility", Journal of World Business, 51, pp. 127-141.

Câmara, Pedro (2011), “A expatriação em Portugal”, Lisboa, Editora RH.

Cerdin, Jean-Luc, e Chris Brewster (2014), "Talent management and expatriation: bridging two streams of research and practice", Journal of World Business, 49, pp. 245-252.

Costas, Jana (2013), "Problematizing mobility: a metaphor of stickiness, non-places and the kinetic elite", Organization Studies, 34 (10), pp. 1467-1485.

Deleuze, Gilles, e Félix Guattari (2004), A Thousand Plateaus, Londres, Continuum.

Doherty, Noeleen, e Michael Dickmann (2009), “Exposing the symbolic capital of international assignments", International Journal of Human Resource Management, 20 (2), pp. 301-320.

Dubet, François (1996 [1994]), Sociologia da Experiência, Lisboa, Instituto Piaget.

Eisenhardt, Kathleen, e Melissa Graebner (2007), “Theory building from cases: opportunities and challenges", Academy of Management Journal, 50, pp. 25-32.

Galbraith, Jay (2000), Designing the Global Corporation, São Francisco, Jossey-Bass.

Giddens, Anthony (1989 [1984]), A Constituição da Sociedade, São Paulo, Livraria Martins Fontes.

Habermas, Jurgen (1985), Le Discours Philosofique de la Modernité, Paris, Gallimard.

Halsberger, Arno, e Chris Brewster (2008), “The expatriate family: an international perspective", Journal of Managerial Psychology, 23 (3), pp. 324-346.

Hippler, Thomas, Chris Brewster, e Arno Haslberger (2015), “The elephant in the room: the role of time in expatriate adjustment", The International Journal of Human Resource Management, 26 (15), pp. 1920-1935.

Kraimer, Maria, Margaret Shaffer, Yu-Ping Chen, e Mark Bolino (2012), “Choices, challenges and career consequences of global work experiences: a review and future agenda", Journal of Management, 2, pp. 1282-1327.

Kraimer, Maria, Mart Bolino, e Brandon Mead (2016), “Themes in expatriate and repatriate research over four decades: what do we know and what do we still need to learn?", Annual Review of Organizational Psychology and Organizational Behavior, 3, pp. 83-109.

Lämsäa, Anna-Maija, Suvi Heikkinen, Mark Smith, e Christelle Tornikoski (2016), “The expatriate's family as a stakeholder of the firm: a responsibility viewpoint", The International Journal of Human Resource Management, 28 (20), pp. 2916-2935.

McNulty, Yvonne, e Chris Brewster (2017), “Theorizing the meaning(s) of 'expatriate': establishing boundary conditions for business expatriates", The International Journal of Human Resource Management, 28 (1), pp. 27-61. 
Osland, Joyce (2000), “The journey inward: expatriate hero tales and paradoxes", Human Resource Management, 39, pp. 227-238.

Peixoto, João (1998), As Migrações dos Quadros Altamente Qualificados em Portugal. Fluxos Migratórios Inter-Regionais e Internacionais e Mobilidade Intra-Organizacional, Lisboa, Instituto Superior de Economia e Gestão, Universidade Técnica de Lisboa, tese de doutoramento.

Ragin, Charles, e Lisa Amoroso (2011), Constructing Social Research. The Unity and Diversity of Method, Nova Iorque, Sage.

Reynaud, Emmanuelle (1992), “Identité collective et changement social: les cultures collectives comme dynamique d'action", Sociologie du Travail, 2, pp. 159-177.

Rousseau, Denise (1995), Psychological Contract in Organizations. Understanding Written and Unwritten Agreements, Newbury Park, CA, Sage.

Shenton, Andrew, e Susan Hayter (2004), "Strategies for gaining access to organizations and informants in qualitative studies", Education for Information, 22, pp. 223-231.

Strauss, Anselm, e Juliet Corbin (1998), Basics of Qualitative Research. Techniques and Procedures for Developing Grounded Theory, Thousand Oaks, CA, Sage.

Tarde, Gabriel (2007 [1893]), Monadologia, Sociologia e Outros Ensaios, São Paulo, Cosac Naify.

João Vasco Coelho. Investigador no Centro de Investigação e Estudos de Sociologia (CIES-Iscte), Iscte - Instituto Universitário de Lisboa,

E-mail:vasco.jcoelho@gmail.com

Receção: 17 de dezembro de 2018 Aprovação: 18 de julho de 2019 